OPEN ACCESS

Edited by:

Xihui Shen,

Northwest A\&F University, China

Reviewed by:

Zongmin Du

Beijing Institute of Microbiology and

Epidemiology, China

${ }^{*}$ Correspondence:

Yi-Cheng Sun

sunyicheng@hotmail.com

Received: 22 November 2017 Accepted: 12 December 2017 Published: 12 January 2018

Citation:

Ren G-X, Guo X-P and Sun Y-C (2018) Corrigendum: HmsC Controls Yersinia pestis Biofilm Formation in Response to Redox Environment. Front. Cell. Infect. Microbiol. 7:525.

doi: $10.3389 /$ fcimb.2017.00525

\section{Corrigendum: HmsC Controls Yersinia pestis Biofilm Formation in Response to Redox Environment}

\author{
Gai-Xian Ren, Xiao-Peng Guo and Yi-Cheng Sun* \\ $\mathrm{MOH}$ Key Laboratory of Systems Biology of Pathogens, Institute of Pathogen Biology, Chinese Academy of Medical \\ Sciences and Peking Union Medical College, Beijing, China
}

Keywords: HmsC, biofilm formation, Yersinia pestis, HmsD, c-di-GMP

\section{A corrigendum on}

HmsC Controls Yersinia pestis Biofilm Formation in Response to Redox Environment by Ren, G.-X., Guo, X.-P., and Sun, Y.-C. (2017). Front. Cell. Infect. Microbiol. 7:355. doi: $10.3389 /$ fcimb.2017.00355

In the original article, the order of the funders in the funding statement was incorrect. It should read:

This work was supported by the National Major Research \& Development Program of China (2016YFC1202600), the National Basic Research Program of China (973 Program) (2015CB554200), the National Natural Science Foundation of China (81501723) and (31670139) and CAMS Initiative for Innovative Medicine (2016-I2M-1-013).

The authors apologize for this error and state that it does not affect the conclusions of the article in any way.

The original article has been updated.

Conflict of Interest Statement: The authors declare that the research was conducted in the absence of any commercial or financial relationships that could be construed as a potential conflict of interest.

Copyright $\odot 2018$ Ren, Guo and Sun. This is an open-access article distributed under the terms of the Creative Commons Attribution License (CC BY). The use, distribution or reproduction in other forums is permitted, provided the original author(s) or licensor are credited and that the original publication in this journal is cited, in accordance with accepted academic practice. No use, distribution or reproduction is permitted which does not comply with these terms. 